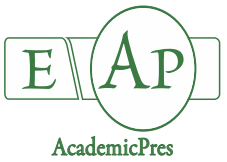

Plesoianu AM et al. (2020)

Notulae Botanicae Horti Agrobotanici Cluj-Napoca 48(1):90-101

DOI: $10.15835 /$ nbha48111828

Research Article

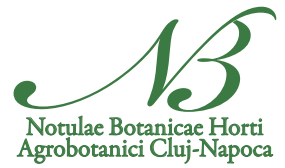

\title{
Postharvest antimicrobial treatments with organic acids to improve the shelf life of fresh blueberries
}

\author{
Alina Madalina PLESOIANU ${ }^{1}$, Felicia TUTULESCU², \\ Violeta NOUR ${ }^{1,2 *}$ \\ 1 "Dunarea de Jos" University of Galati, Faculty of Food Science and Engineering, 111 Domneasca Street, 800201 Galati, \\ Romania; alina.plesoianu20@gmail.com; vionor@yahoo.com ("correspondingauthor) \\ ${ }^{2}$ University of Craiova, Department of Horticulture and Food Science, 13 A. I. Cuza Street, 200585 Craiova, \\ Romania;felixdragomir@yahoo.com
}

\begin{abstract}
Fresh highbush blueberries (Vaccinium corymbosum L.) are one of the most popular soft fruits characterized by attractive sensorial attributes and high antioxidant potential. They are highly perishable as they are susceptible to various microbial infections, both pre- and postharvest. The present research was conducted to investigate the effects of postharvest treatments with citric (2\%), benzoic $(0.2 \%)$ and sorbic $(0.2 \%)$ acids on physicochemical, biochemical and microbiological evolution of fresh blueberries under cold storage conditions. Samples were evaluated initially and at 7-day interval for dry matter, total soluble solids, titratable acidity, total phenolic content, total flavonoid content, antioxidant activity and surface microbial load for six weeks storage time. Chemical treatments significantly reduced the microbial growth on the fruit surface throughout the storage period as compared to the control samples, but they caused a significant increase in moisture loss (sorbic acid > benzoic acid > citric acid > water), probably due to the partial damage of the natural cuticular wax layer covering the fruit. Antimicrobial effects of chemical treatments were more noticeable than their biochemical effects. Total phenolic, total flavonoid content and antioxidant activity showed similar variation pattern during storage in treated and control samples. However, at the end of the storage period, antioxidant activity was significantly higher in samples treated with citric acid and benzoic acid as compared with control samples.
\end{abstract}

Keywords: antioxidant activity; benzoic acid; citric acid; cold storage; microbial growth; sorbic acid

\section{Introduction}

Highbush blueberries are the fruits of a cultivated species, Vaccinium corymbosum L., a deciduous flowering shrub originating from North America. Nowadays blueberries are widely consumed worldwide and often labelled as superfoods due to their high antioxidant potential and multiple health-beneficial effects (Proestos, 2018; Lafarga et al., 2018). Blueberries have been reported to have anticarcinogenic, antiinflammatory, and antimicrobial activities (Chatterjee et al., 2004), along with other positive effects in 
cardiovascular diseases (Ziberna et al., 2010), diabetes, as well as in improved vision (Kowluru et al., 2001), neuroprotection (Galli et al., 2006) and cognitive health (Dodd et al., 2019). These effects have been attributed to their high content of flavonoids, phenolic acids, and stilbenes, but especially to their richness in anthocyanins, the compounds which are responsible for their deep blue color (Moze et al., 2011).

Blueberries are perishable soft fruits, their quality may deteriorate rapidly because of the postharvest respiration, transpiration, and microbial attack (Abugoch et al., 2015; Sun et al., 2014). The shelf-life of fresh blueberries at cold storage temperatures $\left(2-4^{\circ} \mathrm{C}\right)$ was found to be of $10-40$ days, depending on the cultivar type, stage of fruit ripeness, harvest method, presence of fruit disease, and storage conditions (Almenar et al., 2010). The main detrimental factors in postharvest storage and marketing of blueberries are the loss of firmness and microbial decay (Connor et al.2002; Li et al., 2011).

Pre- and postharvest applications of fungicides, cold storage, gamma and UV irradiation, modified atmosphere packaging and ozonation have been used to reduce postharvest deterioration, prolong shelf-life, and retain the nutritional quality of fresh blueberries during storage (Connor et al., 2002; Chiabrando et al., 2006; Trigo et al., 2006; Zheng et al., 2003, 2008). In addition, edible coatings have been studied for extending shelf life of ready-to-eat blueberries (Duan et al., 2011; Yang et al., 2014).

The surface treatment of fruits with various synthetic chemicals is a good strategy for inhibiting the growth of microorganisms in order to improve the shelf life of fresh and fresh-cut fruits (Geransayeh et al., 2012). The antimicrobial action of organic acids was attributed to $\mathrm{pH}$ reduction, disturbance of membrane transport and/or permeability, anion accumulation, inhibition of enzymes, cytoplasm acidification (Parish et al., 2003), as well as to the specific antimicrobial effect of particular anionic species (Ramos-Villarroel et al., 2015). The inhibitory effect of organic acids increases with decreasing $\mathrm{pH}$ as it has been reported to be determined mainly by the undissociated form of the molecule, which diffuses through the microbial cell membrane depending on the $\mathrm{pH}$ gradient between the cytoplasm of the cell and the food matrix surrounding it (Rahman, 2007).

Citric and ascorbic acids are commonly used in fruit and vegetable washing (Velázquez et al., 2009; Ramos et al., 2013) while other acids, such as propionic, sorbic, and benzoic acids, have been used for many years as food and drink preservatives. Akbas and Olmez (2007) reported that lactic and citric acid dipping could be alternative treatments to chlorine dipping to prolong the shelf life of fresh-cut iceberg lettuce while Pusik et al. (2018) found that treatment with $0.5 \%$ solution of citric acid, $0.2 \%$ benzoic acid, $0.05 \%$ sorbic acid increased the shelf life of broccoli. Jiang et al. (2004) reported that $0.1 \mathrm{M}$ citric acid extended the shelf life, inhibited surface coloration and disease development, and reduced the loss in eating quality of fresh-cut Chinese water chestnut while Pao and Petracek (1997) demonstrated that infusion of peeled oranges with citric acid solution $(0.1,0.25,0.5$, and $1.0 \% \mathrm{w} / \mathrm{v})$ during the peeling process reduced the surface $\mathrm{pH}$ of peeled fruits and extended their shelf life due to the inhibition of spoilage bacteria. In contrast, some previous studies reported no significant effect of organic acids (citric or ascorbic acid) on the shelf-life of mango (Vilas Boas et al., 2004; de Souza et al., 2006).

The aim of this study was to evaluate the potential of postharvest dips in organic acids solutions ( $2 \%$ citric acid, $0.2 \%$ benzoic acid and $0.2 \%$ sorbic acid) to preserve the postharvest quality of fresh blueberries. The study determined the surface microbial load, the weight loss and the physicochemical properties, total phenolic compounds, total flavonoids and antioxidant capacity of the fruit during six weeks of refrigerated storage. 


\section{Materials and Methods}

Reagents

Analytical grade chemicals: methanol, Folin-Ciocalteu reagent, gallic acid, quercetin, 2,2-diphenyl-1picrylhydrazyl (DPPH), 6-hydroxy-2,5,7,8-tetramethylchroman-2-carboxylic acid (Trolox) and sodium acetate were purchased from Sigma-Aldrich (Germany); sodium carbonate and aluminum nitrate from Merck (Darmstadt, Germany).

\section{Blueberries}

Highbush blueberries collected at their commercial harvest maturity were procured from a local market in Craiova, Romania.

\section{Treatments and experimental design}

The fruits were sorted on the basis of uniformity in size, colour, and absence of visible injury, placed in PET trays (100 g blueberries in each tray) and then divided into five lots. Fruits of the first three lots were dipped for $5 \mathrm{~min}$ in aqueous solutions of $2 \%$ citric acid (P1), $0.2 \%$ benzoic acid (P2) and $0.2 \%$ sorbic acid (P3). Control blueberries were dipped for $5 \mathrm{~min}$ in distilled water (M) while the fifth lot was kept untreated (M0). After treatment the fruits were dried with a fan for 10 minutes and cooled to storage temperature. All blueberry samples were stored at a temperature of $8 \pm 1^{\circ} \mathrm{C}$ and a relative humidity of $70-75 \%$. Three replications were performed for each treatment. Analysis of blueberry fruits were carried out in dynamics every 7 days during 6 weeks storage. Samples were subjected to the following physicochemical analyses: natural weight loss, total soluble solids, titratable acidity, total phenolic content, total flavonoid content and DPPH radical scavenging activity.

Weight loss

Weight loss (\%) was calculated as the difference between initial and final weight of currently tested blueberry fruits, divided by the initial weight for each replicate.

\section{Total soluble solids}

Homogenous sample was prepared by blending twenty fruits from each treatment in an electrical blender. The total soluble solids content was determined by using a digital refractometer (Hanna Instruments, Woonsocket, USA) and the results were expressed in percentages.

\section{Titratable acidity}

The titratable acidity was measured by the titrimetric method using phenolphthalein as an indicator and the results were expressed as \% citric acid.

\section{Total phenolic content}

Extraction was done by taking $3 \mathrm{~g}$ of fruit tissue homogenized with $10 \mathrm{ml}$ of methanol in an ultrasonic bath for $60 \mathrm{~min}$ at room temperature. After filtering, the process was repeated for residue. Finally, the extracts were combined and diluted to $50 \mathrm{ml}$ with methanol. Total phenolic content was assessed according to the Folin-Ciocalteu phenol reagent method as described by Singleton and Rossi (1965). $100 \mu \mathrm{L}$ of each extract were mixed with $5 \mathrm{~mL}$ of distilled water and $500 \mu \mathrm{L}$ of Folin-Ciocalteu reagent. After $30 \mathrm{sec}$ to $8 \mathrm{~min}, 1.5 \mathrm{~mL}$ of $20 \%$ sodium carbonate was added and the reaction mixture was diluted with distilled water to a final volume of $10 \mathrm{~mL}$. After incubation for $30 \mathrm{~min}$ at $40{ }^{\circ} \mathrm{C}$, the absorbance was measured at $765 \mathrm{~nm}$ on a Varian Cary 50 UV spectrophotometer (Varian Co., USA). The results were expressed as mg gallic acid equivalents (GAE) per 100 fresh weight $(\mathrm{fw})$. 
Total flavonoid content

The total flavonoid content was assessed by the aluminium nitrate spectrophotometric method described by Mohammadzadeh et al. (2007). $0.5 \mathrm{~mL}$ fruit extract prepared as described above was mixed with $0.1 \mathrm{~mL}$ aluminium nitrate (10\%), $0.1 \mathrm{~mL}$ sodium acetate $(1 \mathrm{M})$ and $4.3 \mathrm{~mL}$ methanol. After incubation for 40 min at room temperature, the absorbance of the mixture was measured at $415 \mathrm{~nm}$ on a Varian Cary $50 \mathrm{UV}$ VIS spectrophotometer (Varian Co., USA). The results were expressed as mg of quercetin equivalents (QE) per 100 fresh weight (fw).

\section{Antioxidant activity}

The antioxidant activity was measured using the DPPH (2,2-diphenyl-1-picrylhydrazil) assay. The extraction of samples was made according to the same protocol described for total phenolic content. The free radical scavenging ability of the extracts against DPPH free radical was evaluated as described by Oliveira et al. (2008). $50 \mu \mathrm{L}$ fruit extract was mixed with $3 \mathrm{~mL}$ DPPH methanolic solution (0.004\%). After incubation in the dark for $30 \mathrm{~min}$ at room temperature, the absorbance was measured at $517 \mathrm{~nm}$ on a Varian Cary $50 \mathrm{UV}$ VIS spectrophotometer. The results were expressed in mmol Trolox per $100 \mathrm{~g}$ fresh weight ( $\mathrm{fw}$ ).

\section{Microbiological analysis}

The microbiological analysis was performed by conventional culture techniques. The microorganisms were sampled from the fruits surface using sterile swabs and inoculated on nutrient Agar plates. Every inoculated plate was incubated at $30^{\circ} \mathrm{C}$ for 48 hours. After the incubation time, the developed colonies were counted, and their morphology was studied. Observations were made on the cultural characteristics of the colonies (time of appearance of colonies, degree of development, type of colonies, appearance, color, degree of transparency, consistency). The cultural tests were completed with microscopic, physiological and biochemical tests. The microbial load on the fruit surface was calculated from the number of colonies grown on the plates and it was expressed in $\mathrm{CFU} / \mathrm{cm}^{2}$.

\section{Statistical analysis}

All assays were conducted in triplicate and results are reported as mean \pm standard deviation. The analysis of variance (ANOVA) was done to assess the effects of treatments and storage time. Means comparisons were made using LSD test and statistical significance was identified at $\mathrm{P}<0.05$. The data analysis was performed using the Statgraphics Centurion XVI software (StatPoint Technologies, VA, USA).

\section{Results and Discussion}

\section{Weight loss}

The weight loss of blueberry fruits increased during storage at $8^{\circ} \mathrm{C}$ and $70-75 \%$ relative humidity (Figure 1). As expected, weight loss was very high in this study considering that, in order to minimize weight loss of blueberries, it is crucial to maintain low temperatures $\left(0-1{ }^{\circ} \mathrm{C}\right)$ and high relative humidity (90-95\%) during storage (Concha-Meyer et al., 2015). No significant differences were found in weight loss between the undipped blueberries (M0) and those dipped in water (M). The weight loss of control fruits (M0 and M) was significantly lower than for the chemical treated fruits throughout the storage period. The major cause of weight loss during storage is the migration of water from the fruit to the environment, which, in the case of blueberries, is strongly influenced by the presence of the natural protective wax bloom on their surface. Chemical treatments determined a significant increase in moisture loss (sorbic acid $>$ benzoic acid $>$ citric acid $>$ water), probably due to the partial dissolution of this natural hydrophobic layer covering the fruit. 


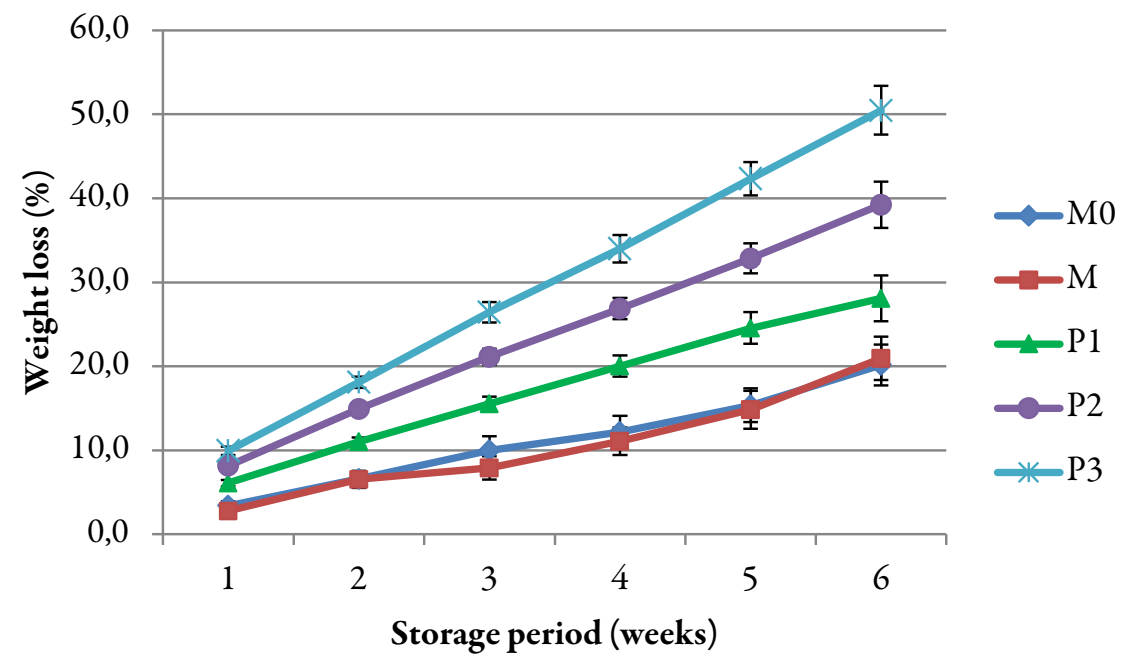

Figure 1. Weight loss of blueberry fruits during cold storage in relation to postharvest treatments with different organic acids (M0 - untreated fruits; M - fruits dipped in distilled water; $\mathrm{P} 1$ - fruits dipped in 2\% citric acid; P2 - fruits dipped in $0.2 \%$ benzoic acid; P3 - fruits dipped in $0.2 \%$ sorbic acid)

\section{Total soluble solids}

The results of total soluble solids (TSS) of blueberry fruits as affected by different treatments are shown in Figure 2. At the end of the storage period, chemical treated fruits exhibited significantly higher mean total soluble solids than control fruits. Higher TSS of treated fruits as compared to control samples could be due to the higher weight loss and to a stimulation of the metabolic activity of the fruits as a result of the weakening of the cuticular wax, which is the first protective barrier against biotic and abiotic stresses (Loypimai et al., 2017; Chu et al., 2018).

\section{Titratable acidity}

Citric acid is the main organic acid present in highbush blueberries and titratable acidity (TA) levels were found to be around $0.3-0.6 \mathrm{~g} / 100 \mathrm{~g}$ (Figure 3). TA was relatively stable in the first three weeks of storage with no significant differences $(\mathrm{P}>0.05)$ in TA found between the control and the treated samples. In the next two weeks, TA values increased and then declined in the last storage week. The control samples had significantly lower TA value than the treated samples during the last three weeks of storage. The initial increase of the titratable acidity could be attributed to the weight loss of the fruits while the decrease of TA in the later storage time is due to the consumption of organic acids in respiratory processes (Kaur et al., 2019).

\section{Totalphenolic content}

Blueberries (Vaccinium spp.) may be considered one of the most valuable sources of antioxidants among fruits and vegetables as a result of their high content of flavonoids (especially anthocyanins), tannins and phenolic acids in the fruits (Vrhovsek et al., 2012; Wang et al., 2012).

Variation of total phenolic content (TPC) of fruits subjected to different chemical treatments during cold storage is presented in Figure 4. Relative to the initial storage time, TPC of fruits increased continuously in the first 5 weeks of storage, but dropped thereafter. The increase of TPC in blueberries during storage was reported in previous studies and it was attributed to the moisture loss but also to the fact that, during storage, blueberry fruits gradually generated phenolic compounds (Connor et al., 2002; Yang et al., 2014). The highest total phenolic content was found in fruits dipped in $0.2 \%$ sorbic acid, probably as a result of the highest moisture loss found in these fruits. 


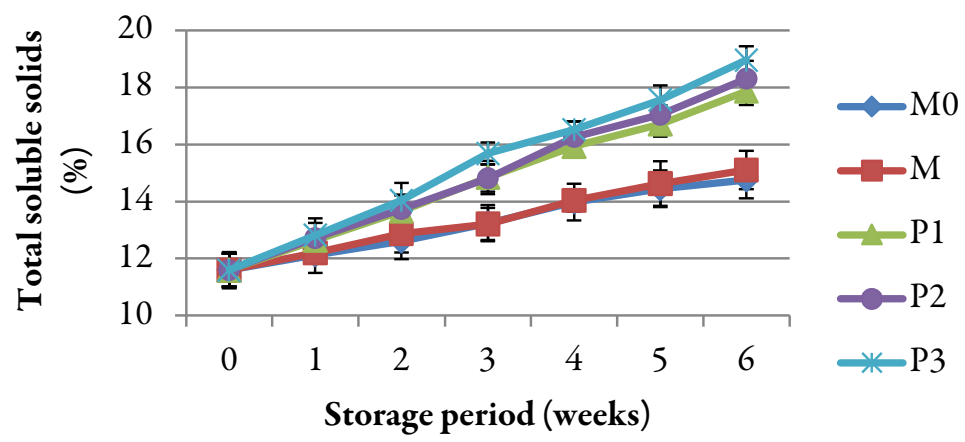

Figure 2. Variation of total soluble solids in blueberry fruits during cold storage in relation to postharvest treatments with different organic acids (M0 - untreated fruits; M - fruits dipped in distilled water; P1 fruits dipped in $2 \%$ citric acid; P2 - fruits dipped in $0.2 \%$ benzoic acid; P3 - fruits dipped in $0.2 \%$ sorbic acid)

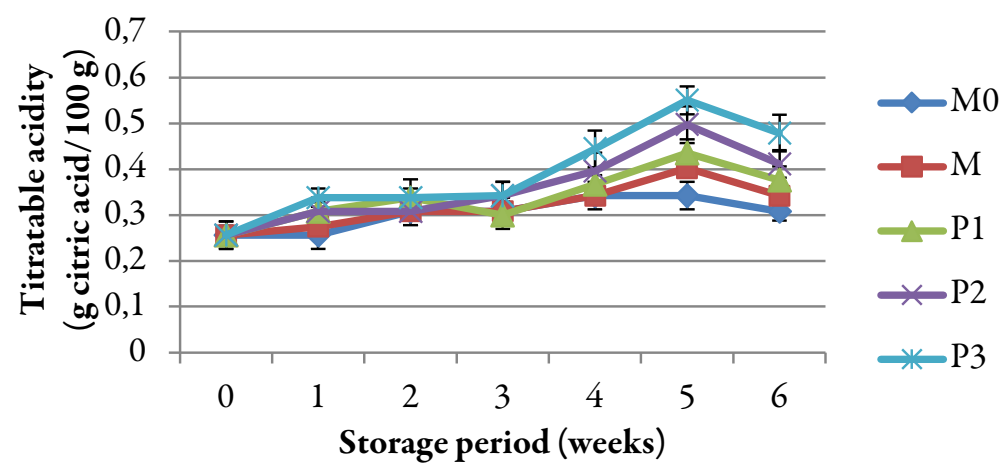

Figure 3. Variation of titratable acidity in blueberry fruits during cold storage $\left(5-8{ }^{\circ} \mathrm{C}\right)$ in relation to postharvest treatments with different organic acids (M0 - untreated fruits; $\mathrm{M}$ - fruits dipped in distilled water; P1 - fruits dipped in 2\% citric acid; P2 - fruits dipped in $0.2 \%$ benzoic acid; P3 - fruits dipped in $0.2 \%$ sorbic acid)

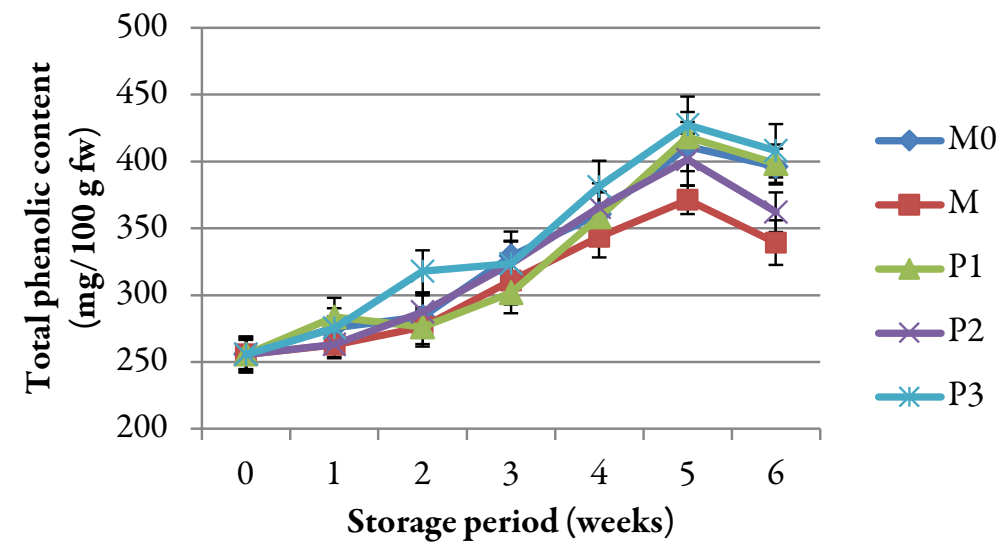

Figure 4. Variation of total phenolic content in blueberry fruits during cold storage in relation to postharvest treatments with different organic acids (M0 - untreated fruits; $\mathrm{M}$ - fruits dipped in distilled water; P1 - fruits dipped in 2\% citric acid; P2 - fruits dipped in $0.2 \%$ benzoic acid; P3 - fruits dipped in $0.2 \%$ sorbic acid) 


\section{Total flavonoid content}

The total flavonoid content showed a variation similar to that of the total phenolic content, with a continuous increase during the first five weeks of storage (Figure 5). The highest increases were recorded in acid-dipped samples compared to the control samples, probably due to the higher moisture loss of these fruits. Many previous studies also reported increases in total phenolic and total anthocyanin content in highbush blueberry (Kalt et al., 1999; Connor et al., 2002) and lowbush blueberries (Kalt and McDonald, 1996) during storage. Increases in total phenolic and total anthocyanin content were also observed in blueberries stored in high oxygen atmosphere (Zheng et al., 2003).

\section{Antioxidant activity}

In all samples, the antioxidant activity increased in the first week of refrigerated storage, it was stable in the next two weeks and declined significantly in the last three weeks of storage (Figure 6). Results reported by Connor et al. (2002) demonstrated that increases in antioxidant activity, total phenolic content, and anthocyanin content may occur in blueberry fruits during the first three weeks of cold storage. The decrease in antioxidant activity recorded during the last three weeks of storage can be attributed to the degradation of anthocyanins, possibly due to oxidations and/or condensation reactions with other phenolic compounds (Reque et al., 2014). The most important decrease in antioxidant activity was recorded in the last week of storage, which correlates with the significant decrease in the total phenolic content registered during the same period. Many previous studies demonstrated that, in blueberries, the phenolic and the anthocyanin content were significantly correlated with antioxidant capacity (Kalt et al., 1999; Jakobek et al., 2007). However, after six weeks of cold storage, the highest antioxidant activity was found in the fruits dipped in $2 \%$ citric acid ( 0.76 mmol Trolox/100 $\mathrm{g} \mathrm{fw}$ ), even if the content of phenolic compounds was lower than in other samples.

\section{Microbial growth}

Immediately after treatment, the highest microbial load was recorded on the control samples (M0, without treatment). Isolated as well as confluent colonies were formed on the culture medium, giving a lawn of colonies on the plate. Morphological analysis of the colonies and microscopic examination revealed a substantial microbial diversity on the untreated control sample (M0), including several deteriorative microorganisms from the genera Bacillus, Pseudomonas, Alternaria, Rhizopus, Saccharomyces and Rhodotorula.

Washing with water is the simplest treatment for reducing the microbial load, especially on fruits and vegetables. This leads to the removal of microorganisms that are not very adherent to the surface of the fruit, especially from the fruits covered with a protective waxy layer. In the case of blueberries, washing with distilled water led to a considerable reduction in the number of microorganisms as compared to the control sample. However, Bacillus bacteria and Saccharomyces yeasts were found on the fruit surface.

After 48 hours of incubation, no colonies were detected on the culture media from the samples treated with $2 \%$ citric acid (P2). Re-incubation for another 24 hours did not change the result. This can be explained by the inhibitory effect of the low $\mathrm{pH}$ on the metabolic activity of microorganisms. The permeability of the acid is the higher the $\mathrm{pH}$ of the medium is lower. The same microflora inhibition was observed at the fruits dipped in $0.2 \%$ benzoic acid with no colonies grown in 48 hours incubation time. It is well known that, at low $\mathrm{pH}$, benzoic acid is an effective antimicrobial agent for the control of bacteria, yeasts and molds (del Olmo et al., 2017). Sorbic acid, a well-known antifungal, did not inhibit the Rhizopus mold, that has developed on samples dipped in $0.2 \%$ sorbic acid (P3) immediately after fruit immersion.

After 7 days of refrigerated storage, it was found a high microbial load on the samples without chemical treatment (M0 and M), much higher on untreated samples (M0), and only a small number of colonies have been grown from samples dipped in $2 \%$ citric acid $\left(3 \mathrm{CFU} / \mathrm{cm}^{2}\right)$ or in $0.2 \%$ benzoic acid $\left(2 \mathrm{CFU} / \mathrm{cm}^{2}\right)$. Sorbic acid exhibited the same antimicrobial activity against bacteria and yeasts, inhibited most molds but still allowed 
the growth of the Rhizopus mold. The microorganisms grown on the agar plates from fruits surface after 7 days of refrigerated storage are presented in Table 1.

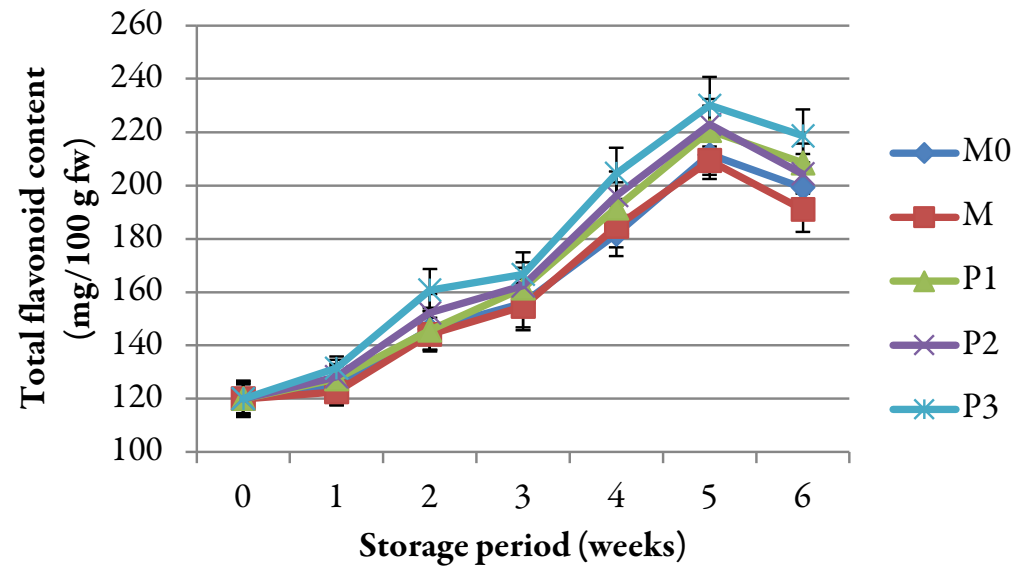

Figure 5. Variation of total flavonoid content in blueberry fruits during cold storage in relation to postharvest treatments with different organic acids (M0 - untreated fruits; $\mathrm{M}$ - fruits dipped in distilled water; P1 - fruits dipped in 2\% citric acid; P2 - fruits dipped in $0.2 \%$ benzoic acid; P3 - fruits dipped in $0.2 \%$ sorbic acid)

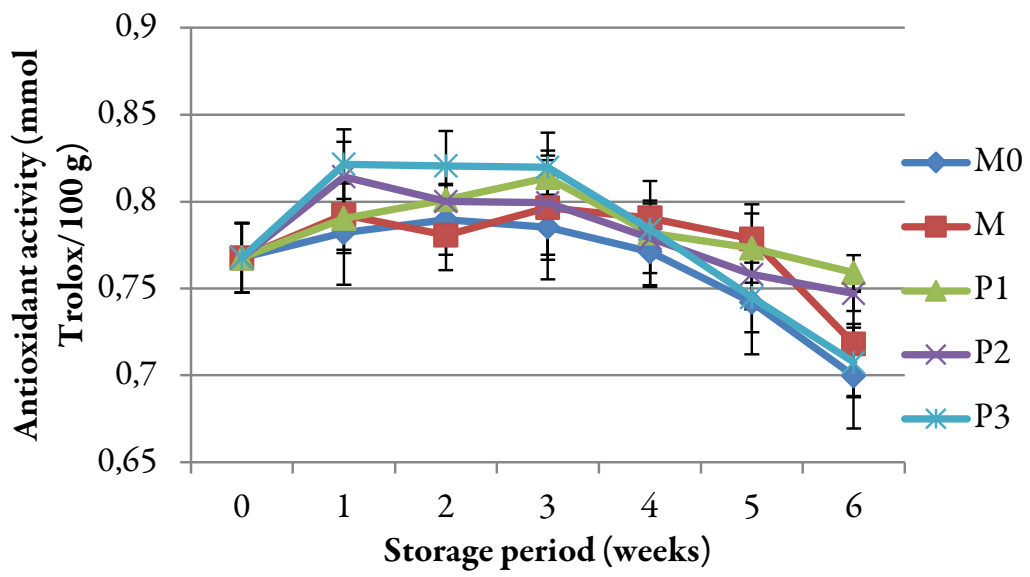

Figure 6. Variation of antioxidant activity in blueberry fruits during cold storage in relation to postharvest treatments with different organic acids (M0 - untreated fruits; M - fruits dipped in distilled water; P1 fruits dipped in $2 \%$ citric acid; P2 - fruits dipped in $0.2 \%$ benzoic acid; P3 - fruits dipped in $0.2 \%$ sorbic acid)

Table 1. Microorganisms grown on the agar plates from fruits surface after 7 days of refrigerated storage*

\begin{tabular}{|c|c|c|c|c|}
\hline \multicolumn{5}{|c|}{ Sample } \\
\hline M0 & M & P1 & P2 & P3 \\
\hline Bacillus & Bacillus & Bacillus & Alternaria & Rhizopus \\
Pseudomonas & Saccharomyces & Saccharomyces & Aspergillus & \\
Alternaria & Pseudomonas & Alternaria & & \\
Rhizopus & Alternaria & & & \\
Saccharomyces & Rhizopus & & & \\
Rhodotorula & & & & \\
\hline
\end{tabular}


After 3 weeks of refrigerated storage it was found that the Rhizopus molds, the Saccharomyces yeasts and the sporulated Bacillus bacteria were resistant to refrigeration. In addition, the Pseudomonas bacteria was found on fruit surface.

The untreated fruits (M0) showed a very high microbial load accompanied by the texture softening, while a lower microbial load was found on fruits dipped in water (M). Bacteria of the genus Pseudomonas prevailed on these samples, forming confluent colonies that covered almost the entire surface of the culture medium after 48 hours of inoculation. Bacteria from the genus Bacillus have also developed, as well as a small number of molds from the genera Rhizopus and Alternaria.

The surface microbial load of the samples dipped in $2 \%$ citric acid (P1) increased slightly $\left(8 \mathrm{CFU} / \mathrm{cm}^{2}\right.$ after 3 weeks compared to $3 \mathrm{CFU} / \mathrm{cm}^{2}$ after one week of refrigerated storage). Benzoic acid (0.2\%) had a stronger antimicrobial effect compared to $2 \%$ citric acid, only $4 \mathrm{CFU} / \mathrm{cm}^{2}$ grew from samples dipped in $2 \%$ benzoic acid after 3 weeks of cold storage. The treatment with $0.2 \%$ sorbic acid inhibited all yeasts and bacteria, but showed a weak action against the Rhizopus mold.

After 6 weeks of cold storage, the untreated blueberry fruits presented high microbial counts on surface, with Rhizopus mold predominating, followed by Alternaria, many Saccharomyces and Rhodotorula yeasts, Bacillus and Pseudomonas bacteria. The microflora grown on the fruits dipped in water (M) after 6 weeks of storage consisted of Bacillus and Pseudomonas bacteria and Saccharomyces and Rhodotorula yeasts which predominated over bacteria.

Citric acid (2\%) and low temperature inhibited the microorganisms from blueberries surface during 6 weeks of refrigerated storage. Only a very low number of resistant microorganisms $\left(3 \mathrm{CFU} / \mathrm{cm}^{2}\right)$ were found on the samples dipped in $0.2 \%$ benzoic acid after 6 weeks of cold storage. As the storage period increased, the number of colonies belonging to the Rhizopus mold decreased from the samples dipped in $0.2 \%$ sorbic acid and the colonies were smaller, probably as a result of the low temperature.

\section{Conclusions}

Our results show that post-harvest treatment of blueberry fruits with organic acids determined a significant increase in moisture loss, probably due to the partial dissolution of the natural cuticular wax layer covering the fruit. The total phenolic and total flavonoid content of fruits increased continuously in the first five weeks of storage, but decreased thereafter. Antioxidant activity registered a continuous decrease in the last three weeks of storage. At the end of the storage period, the citric and benzoic acids treated blueberries had significantly higher antioxidant activity as compared with the control samples. Microbiological analysis results indicated that the acid-dipped samples presented a significantly microbial growth inhibition compared to the control samples. Organic acids inhibited bacteria, yeast and mold growth during 6 weeks storage, except sorbic acid which allowed the growth of the Rhizopus mold during five weeks cold storage.

\section{Acknowledgements}

This work benefited from the networking activities within the European funded COST ACTION CA18113 - Understanding and exploiting the impacts of low $\mathrm{pH}$ on micro-organisms. 


\section{Conflict of Interests}

The authors declare that there are no conflicts of interest related to this article.

\section{References}

Abugoch L, Tapia C, Plasencia D, Pastor A, Castro Mandujano O, López L, Escalona V (2015). Shelf-life of fresh blueberries coated with quinoa protein/chitosan/sunflower oil edible film. Journal of the Science of Food and Agriculture 96:619626.

Akbas MY, Olmez H (2007). Effectiveness of organic acid, ozonated water and chlorine dippings on microbial reduction and storage quality of fresh-cut Iceberg lettuce. Journal of the Science of Food and Agriculture 87(14):2609-2616.

Almenar E, Samsudin H, Auras R, Harte J (2010). Consumer acceptance of fresh blueberries in bio-based packages. Journal of the Science of Food and Agriculture 90(7):1121-1128.

Chatterjee A, Yasmin T, Bagchi D, Stohs SJ (2004). Inhibition of Helicobacter pylori in vitro by various berry extracts, with enhanced susceptibility to clarithromycin. Molecular and Cellular Biochemistry 265:19-26.

Chiabrando V, Peano C, Beccaro G, Bounous G, Rolle L (2006). Postharvest quality of highbush blueberry (Vaccinium corymbosum L.) cultivars in relation to storage methods. Acta Horticulturae 715:545-551.

Chu W, Gao H, Chen H, Fang X, Zheng Y (2018). Effects of cuticular wax on the postharvest quality of blueberry fruit. Food Chemistry 239:68-74.

Concha-Meyer A, Eifert JD, Williams RC, Marcy JE, Welbaum GE (2015). Shelf life determination of fresh blueberries (Vaccinium corymbosum) stored under controlled atmosphere and ozone. International Journal of Food Science 164143:1-9.

Connor MA, Luby JJ, Hancock FJ, Berkheimer S, Hanson JE (2002). Changes in fruit antioxidant activity among blueberry cultivars during cold-temperature storage. Journal of Agricultural and Food Chemistry 50:893-898.

de Souza BS, O’Hare TJ, Durigan JF, Souza de PS (2006). Impact of atmosphere, organic acids, and calcium on quality of freshcut 'Kensington' mango. Postharvest Biology and Technology 42:161-167.

del Olmo A, Calzada J, Nuñez M (2017). Benzoic acid and its derivatives as naturally occurring compounds in foods and as additives: Uses, exposure, and controversy. Critical Reviews in Food Science and Nutrition 57(14):3084-3103.

Dodd G, Williams CM, Butler LT, Spencer JPE (2019). Acute effects of flavonoid-rich blueberry on cognitive and vascular function in healthy older adults. Nutrition and Healthy Aging 5(2):119-132.

Duan J, Wu R, Strik B, Zhao Y (2011). Effect of edible coatings on the quality of fresh blueberries (Duke and Elliott) under commercial storage conditions. Postharvest Biology and Technology 59:71-79.

Galli RL, Bielinski DF, Szprengiel A, Shukitt-Hale B, Joseph JA (2006). Blueberry supplemented diet reverses age-related decline in hippocampal Hsp70 neuroprotection. Neurobiology of Aging 27:344-350.

Geransayeh M, Mostofi Y, Abdossi V (2012). Effect of ozonated water on storage life and postharvest quality of Iranian table grape (cv. 'Bidaneh Qarmez'). The Journal of Agricultural Science 4(2):31-38.

Jakobek L, Seruga M, Medvidovic-Kosanovic M, Novak I (2007). Anthocyanin content and antioxidant activities of various red fruit juices. Deutsche Lebensmittel Rundschau 103:58-64.

Jiang Y, Pen L, Li J (2004). Use of citric acid for shelf life and quality maintenance of fresh-cut Chinese water chestnut. Journal of Food Engineering 63:325-328.

Kalt W, Forney CF, Martin A, Prior RL (1999). Antioxidant capacity, vitamin C, phenolics, and anthocyanins after fresh storage of small fruits. Journal of Agricultural and Food Chemistry 47:4638-4644.

Kalt W, McDonald JE (1996). Chemical composition of lowbush blueberry cultivars. Journal of American Society of Horticultural Science 121:142-146.

Kaur A, Gill PPS, Jawandha SK (2019). Effect of sodium benzoate application on quality and enzymatic changes of pear fruits during low temperature. Journal of Food Science and Technology 56(7):3391-3398.

Kowluru RA, Tang J, Kern TS (2001). Abnormalities of retinal metabolism in diabetes and experimental galactosemia. VII. Effect of long-term administration of antioxidants on the development of retinopathy. Diabetes 50:1938-1942. 
100

Lafarga T, Aguiló-Aguayo I, Bobo G, Chung AV, Tiwari BK (2018). Effect of storage on total phenolics, antioxidant capacity, and physicochemical properties of blueberry (Vaccinium corymbosum L.) jam. Journal of Food Processing and Preservation 42(7):e13666.

Li C, Luo J, MacLean D (2011). A novel instrument to delineate varietal and harvest effects on blueberry fruit texture during storage. Journal of the Science of Food and Agriculture 91(9):1653-1658.

Loypimai P, Paewboonsom S, Damerow L, Blanke MM (2017). The wax bloom on blueberry: Application of luster sensor technology to assess glossiness and the effect of polishing as a fruit quality parameter. Journal of Applied Botany and Food Quality 90:154-158.

Mohammadzadeh S, Sharriatpanahi M, Hamedi M, Amanzadeh Y, Sadat Ebrahimi SE, Ostad SN (2007). Antioxidant power of Iranian propolis extract. Food Chemistry 103:729-733.

Moze S, Polak T, Gasperlin L, Koron D, Vanzo A, Poklar Ulrih N, Abram V (2011). Phenolics in Slovenian bilberries (Vaccinium myrtillus L.) and blueberries (Vaccinium corymbosum L.). Journal of Agricultural and Food Chemistry 59:6998-7004.

Oliveira I, Sousa A, Ferreira ICFR, Bento A, Estevinho L, Pereira JA (2008). Total phenols, antioxidant potential and antimicrobial activity of walnut (Juglans regia L.) green husks. Food and Chemical Toxicology 46:2326-2331.

Pao S, Petracek PD (1997). Shelf life extension of peeled oranges by citric acid treatment. Food Microbiology 14:485-491.

Parish ME, Beuchat LR, Suslow TV, Harris LJ, Garrett EH, Farber JN, Busta FF (2003). Methods to reduce/eliminate pathogens from fresh and fresh-cut produce. Comprehensive Reviews in Food Science and Food Safety 2:161-173.

Proestos C (2018). Superfoods: Recent data on their role in the prevention of diseases. Current Research in Nutrition and Food Science 6(3).

Pusik L, Pusik V, Lyubymova N, Bondarenko V, Gaevaya L (2018). Investigation of the influence of antimicrobial preparations on the shelf life of broccoli cabbage. Eureka: Life Sciences 4:13-19.

Rahman MS (2007). Preservation using chemicals and microbes. In: Rahman MS (Ed). Handbook of Food Preservation. CRC Press, 2nd ed, pp 287.

Ramos B, Miller F, Brandão TR, Teixeira P, Silva CL (2013). Fresh fruits and vegetables -an overview on applied methodologies to improve its quality and safety. Innovative Food Science and Emerging Technologies 20:1-15.

Ramos-Villarroel AY, Martín-Belloso O, Soliva-Fortuny R (2015). Combined effects of malic acid dip and pulsed light treatments on the inactivation of Listeria innocua and Escherichia coli on fresh-cut produce. Food Control 52:112-118.

Reque PM, Steffens RS, Jablonski A, Flôres SH, Rios AO, Jong EV (2014). Cold storage of blueberry (Vaccinium spp.) fruits and juice: Anthocyanin stability and antioxidant activity. Journal of Food Composition and Analysis 33(1):111-116.

Singleton VL, Rossi JA (1965). Colorimetry of total phenolics with phosphomolybdic-phosphotungstic acid reagents. American Journal of Enology and Viticulture 16:144-158.

Sun XX, Narciso J, Wang Z, Ference C, Bai JH, Zhou KQ (2014). Effects of chitosan -essential oil coatings on safety and quality of fresh blueberries. Journal of Food Science 79:955-960.

Trigo MJ, Sousa MB, Botelho ML, Veloso G (2006). Quality of gamma irradiated blueberries. Acta Horticulturae 715:573-577.

Velázquez LD, Barbini NB, Escudero M, Estrada C, de Guzman AMS (2009). Evaluation of chlorine, benzalkonium chloride and lactic acid as sanitizers for reducing Escherichia coli O157:H7 and Yersinia enterocolitica on fresh vegetables. Food Control 20(3):262-268.

Vilas Boas BM, Nunes EE, Fiorini FVA, Lima LCO, Vilas Boas EVB, Coelho AHR (2004). Avaliaçãao da qualidade de mangas 'Tommy Atkins' minimamente processadas. Revista Brasileira de Fruticultura 26:540-543.

Vrhovsek U, Masuero D, Palmieri L, Mattivi F (2012). Identification and quantification of flavonol glycosides in cultivated blueberry cultivars. Journal of Food Composition and Analysis 25:9-16.

Wang SY, Chen H, Camp MJ, Ehlenfeldt MK (2012). Genotype and growing season influence blueberry antioxidant capacity and other quality attributes. International Journal of Food Science and Technology 47:1540-1549.

Yang G, Yue J, Gong X, Qian B, Wang H, Deng Y (2014). Blueberry leaf extracts incorporated chitosan coatings for preserving postharvest quality of fresh blueberries. Postharvest Biology and Technology 92:46-53.

Zheng Y, Wang YC, Wang YS, Zheng W (2003). Effect of high-oxygen atmospheres on blueberry phenolics, anthocyanins, and antioxidant capacity. Journal of Agricultural and Food Chemistry 51:7162-7169.

Zheng Y, Yang Z, Chen X (2008). Effect of high oxygen atmospheres on fruit decay and quality in Chinese bayberries, strawberries and blueberries. Food Control 19:470-474. 
Ziberna L, Lunder M, Moze S, Vanzo A, Tramer F, Passamonti S, Drevensek G (2010). Acute cardioprotective and cardiotoxic effects of bilberry anthocyanins in ischemia-reperfusion injury: beyond concentration-dependent antioxidant activity. Cardiovascular Toxicology 10:283-294.

OPEN ACCESS

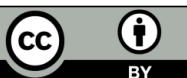

The journal offers free, immediate, and unrestricted access to peer-reviewed research and scholarly work. Users are allowed to read, download, copy, distribute, print, search, or link to the full texts of the articles, or use them for any other lawful purpose, without asking prior permission from the publisher or the author.

License - Articles published in Notulae Botanicae Horti Agrobotanici Cluj-Napoca are Open-Access, distributed under the terms and conditions of the Creative Commons Attribution (CC BY 4.0) License. (C) Articles by the authors; UASVM, Cluj-Napoca, Romania. The journal allows the author(s) to hold the copyright/to retain publishing rights without restriction. 